\title{
Third World Initiatives on Pharmaceuticals: a documentation for the record
}

\author{
Surendra J. Patel
}

The supply of the right drugs at the right prices has become an issue of central concern during the last decade. Many initiatives have contributed to this. Among them, the developing countries have played a key role in centring world attention on the pharmaceutical question and in bringing about changes in the area. This role, however, has been insufficiently documented. The present article therefore reviews some of the main Third World initiatives to promote rational and equitable pharmaceutical policies.

\section{Third World Concern with the Pharmaceutical Question}

The reasons for the deep concern of the developing countries for the drug question are to be found in their dependence on external suppliers for pharmaceuticals. ${ }^{2}$ In 1980 they produced only 11 per cent of the world output. Except for Argentina, Brazil, Egypt, India and Mexico, drug production in developing countries is either wholly non-existent or just limited to formulation and packaging. Even in countries where there is some local production, it is mostly accounted for by wholly-owned subsidiaries of transnational corporations (TNCs) or by joint ventures in which the TNCs dominate. TNCs enjoy a considerable market concentration and domination. Most drugs are sold under a large number of brand names, which often exceed 20,000 in number in a single country. Since doctors and pharmacists mainly determine which drugs are to be used, it has proved easy to establish market control through heavy promotion and sales practices. Most of the research and development ( $R \& D$ ) is concentrated in the developed countries. The combined use of the patent and trade mark systems ensures the dominant producers a large share of the pharmaceutical market. In consequence, the costs of imported drugs for developing countries are excessively high and often account for a third to over a half of their health budgets. The capacity of the developing countries to extend health care to their

${ }^{1}$ The views expressed here are personal and are not to be att ributed to UNCTAD.

${ }^{2}$ For details see UNCTAD 1982a, particularly paragraphs 35-67.

Bulletin, 1983, vol 14 no 4, Institute of Development Studies, Sussex populations is thereby severely constrained. Mounting drug expenditures have limited their policy manoeuvrability to achieve 'Health for All' as called for in the WHO strategy [WHO 1981].

The vulnerability of the developing countries in the world pharmaceutical market was eloquently summarised by Mrs. Indira Ghandi, the Prime Minister of India, in her opening address at the 34th session of the World Health Assembly, which adopted the "Global Strategy for Health for All by the Year 2000':

\begin{abstract}
Affluent societies are spending vast sums of money understandably on the search for new products and processes to alleviate suffering and to prolong life. In the process, drug manufacture has become a powerful industry, subject to the same driving considerations as other big industries, that is, concentration on profit, fierce competition and recourse to hard-sell advertising. Medicines which may be of the utmost value to poorer countries can be bought by us only at exorbitant prices, since we are unable to have adequate independent bases of research and production. This apart, sometimes dangerous new drugs are tried out on populations of weaker countries although their use is prohibited within the countries of manufacture. It also happens that publicity makes us victims of habits and practices which are economically wasteful or wholly contrary to good health . . My idea of a better ordered world is one in which medical discoveries would be free of patents and there would be no profiteering from life or death.
\end{abstract}

\section{The Key Role of the Non-Aligned Conferences}

These concerns have propelled the Third World countries towards the search for rational and equitable pharmaceutical policies. This search has been a part of their initiatives for the establishment of a New International Economic Order. The pharmaceutical question has figured very prominently in these initiatives, of ten guided by decisions at the highest political level. 
In preparation for the 5 th conference of heads of state or government of non-aligned countries held in Colombo in 1976, a Group of Experts on Pharmaceuticals was convened in Georgetown, Guyana, earlier in the same year. The Group had before it the UNCTAD study, Major Issues in Transfer of Technology to Developing Countries: a Case Study of the Pharmaceutical Sector. ${ }^{3}$

The Colombo conference of the non-aligned countries adopted a special resolution (number 25) on the subject. ${ }^{4}$ The resolution endorsed the following actions recommended by the Guyana Group of Experts:

- preparation of a list of priority pharmaceutical needs of each developing country and formulation of a basic model list of such needs as a general guideline for action by developing countries;

- establishment of a national buying agency to undertake the purchase and supply of pharmaceuticals;

- consideration, in the context of the revision of the industrial property system, of the exclusion of pharmaceutical products from the grant of patent rights, or alternatively, of the curtailment of the duration of patents for pharmaceuticals;

- elimination, wherever possible, of brand names and adoption of generic names for pharmaceuticals, and provision of information only from official sources;

- establishment by each developing country of its own pharmaceutical industry as appropriate, beginning with formulation and packaging, and building up to more complex production activities;

- creation of regional cooperative pharmaceutical production and technology centres, as proposed by UNCTAD and UNIDO, to: draw up drug lists; coordinate R\&D; facilitate the transfer of technology; collect and disseminate information on pharmaceutical uses and prices, and on technological capabilities among member countries; and to coordinate the production and exchange of drugs between member countries as well as between regional centres.

The resolution further invited the relevant international bodies, such as UNCTAD, UNIDO, WHO

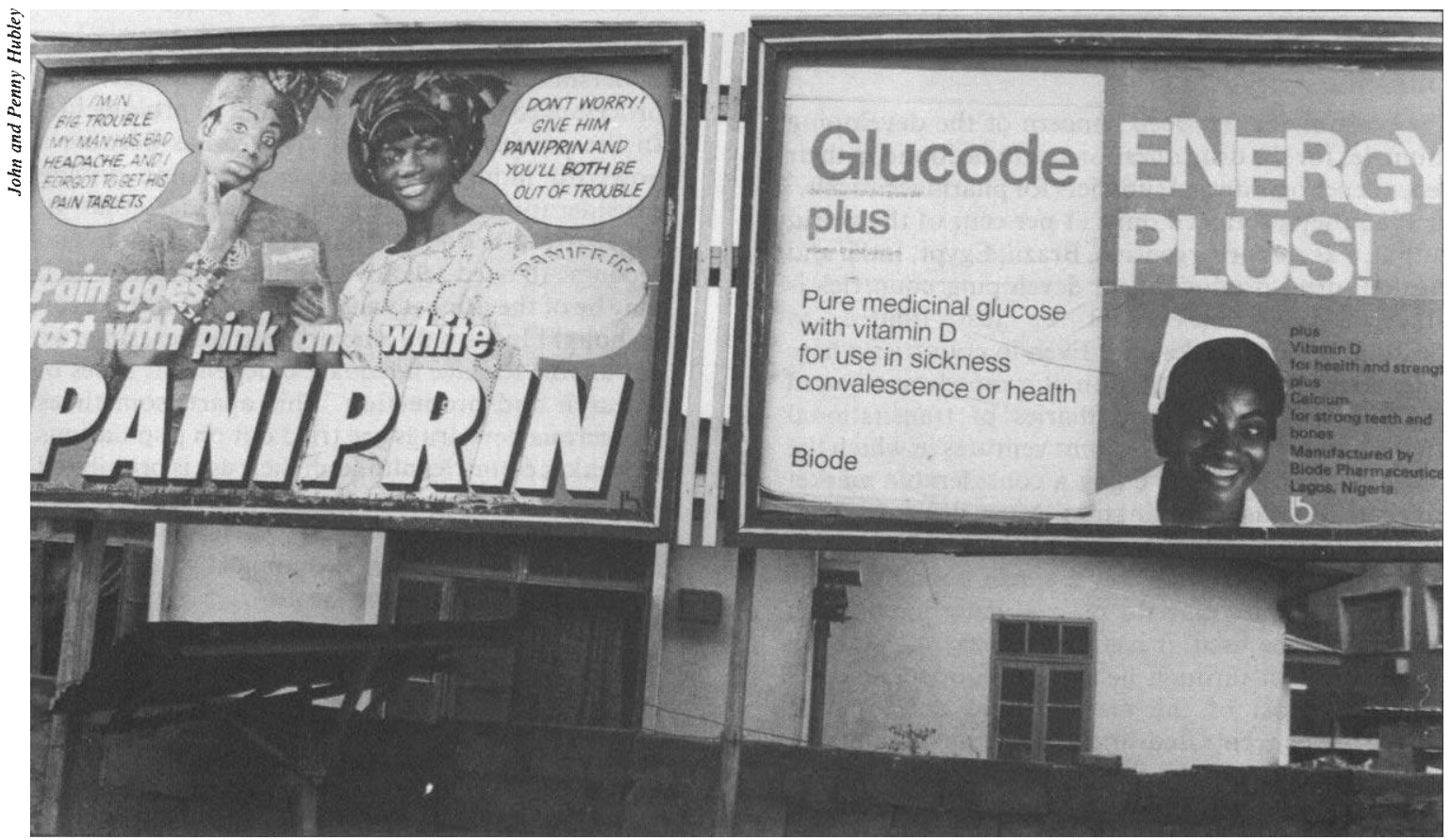

Promotion of proprietary products: a continuing problem

${ }^{3}$ This study has usually been ascribed to $\mathrm{S}$. Lall, but for the historical record, it was published as an UNCTAD document (TD/B/C.6/4) which exaplained that it had been prepared by Dr Sanjaya Lall in cooperation with the UNCTAD secretariat.

${ }^{4}$ For the full text of the resolution see [UNCTAD 1982a:Annex I] or Patel [1983:29l]. and UNDP, to assist in the achievement of the objectives outlined above, particularly through the establishment of appropriate national pharmaceutical centres in developing countries and of regional cooperative pharmaceutical production and technology centres to serve those countries. The Colombo 
non-aligned conference thus delineated the basic lines of the reform of the pharmaceutical system. It opened up new dimensions for concerted action at the national level. It also gave impetus to the involvement of several international bodies, particularly WHO, UNCTAD and UNIDO, in pharmaceutical issues. ${ }^{5}$ For the first time since the Hamurabi Code 4000 years ago (see $\mathbf{p} 77$ ), the drug question became an issue of world concern, involving in it the full political weight of the non-aligned countries at the level of heads of state or government.

Swift international action followed the Colombo conference. A special task force on pharmaceuticals was established by UNCTAD, WHO, UNIDO, the United Nations Department of Technical Cooperation for Development, and the United Nations Action Programme for Economic Cooperation. The task force prepared a project entitled, 'Economic and Technical Cooperation among Developing Countries in the Pharmaceutical Sector', which was approved by UNDP for financing, ${ }^{6}$ and which was executed by the Government of Guyana in cooperation with the involved UN agencies. An interregional mission organised jointly by the various bodies participating in the project visited several developing countries and submitted a report in 1979 under the title, 'Pharmaceuticals in the Developing World: Policies on Drugs, Trade and Production'?

This report of the interregional mission contained 27 practical recommendations for comprehensive measures to be taken by developing countries at the national, regional and interregional levels. They covered a wide range of interrelated issues concerning national pharmaceutical policies such as: essential drugs; quality control; exchange of information; pooled procurement and cooperative bulk purchases; price control of imported drugs; unpackaging of technology imports; excluding pharmaceutical products and processes from patentability or shortening the duration of patents; abolition of trade marks or brand names and introduction of the use of generic names; formulation of new laws and policies; strengthening national $R$ \& D capacity; establishment of national drug production on a well planned and phased basis; promotion of medicinal plants; intensive cooperation among developing countries in exchanging technologies, and establishment of subregional and regional institutional arrangements (eg pharmaceutical centres) to promote such cooperation.

\footnotetext{
${ }^{5}$ United Nations studies and publications on the subject of pharmaceuticals have mushroomed in the last several years. Some of the more important ones are cited in the references under their respective UN agency publication.

'UNDP project INT/009.'A/01/99.

${ }^{7}$ For the full text of the conclusions and recommendations of this report see UNCTAD [1982a:Annex V] or Patel [1983, pp 293-296].
}

This set of recommendations has formed the basis for new pharmaceutical policies in developing countries. They are, however, pertinent also to developed countries, and here is an area where the Third World has given a lead to the developed world.

The report was also considered at the 6 th conference of the heads of state or government of non-aligned countries held in Havana in 1979. The conference endorsed in a special resolution (number 8) the recommendations of the interregional mission and called for the establishment of national and regional centres on pharmaceuticals. ${ }^{8}$ It directed these centres to perform some of the following 14 functions:

- elaboration of drug lists and formularies;

- pooled procurement, inventory control and forecasting systems at the regional level;

- elaboration of legal principles relating to industrial property;

- elaboration of tenders and master contracts for drug imports;

- provision of information on sources of supply and technology;

- assistance in the screening and evaluation of drug imports;

- price monitoring, control of transfer pricing and technology import mechanisms;

- promotion of industrial cooperation among countries;

- assistance in securing equipment imports on the most economic terms;

- organisation of training of government officials in health policy, and drug procurement, production, etc;

- production of pharmaceuticals and intermediates for several countries;

- research in laboratory, pilot plant, semi-industrial and industrial processes for the introduction of new products and the adaptation of imported technologies;

- preparation of feasibility reports on pharmaceutical development projects;

- ensuring of quality control in respect of raw materials, intermediates and finished products.

The Colombo and Havana conferences of the nonaligned countries have thus not only given a composite package of core elements for new pharmaceutical policies, but have also clearly determined the functions of the pharmaceutical centres which must be established to implement the new policies. The three years between the conferences saw perhaps the most active involvement of developing countries in determining the shape of new drug policies and in setting an example for the world to follow.

${ }^{8}$ For the full text of the resolution see UNCTAD [1982a:Annex VI]
or Patel [1983 pp29I-292]. 


\section{Progress Towards New Pharmaceutical Policies}

\section{At the national level}

Following the directives of the non-aligned conferences there was a burst of activity at the national level. Several countries have already introduced some form of central procurement system. As a minimum, almost every country has taken steps towards the coordination of the purchase of drugs for its public health system, particularly for the hospitals operating in the public sector.

A number of developing countries (Argentina, Brazil, India, Egypt and Mexico) have already created fairly advanced production capabilities. Several others have established formulation and packaging units. Others again have at least begun to assess their national drug needs, and to formulate policies and plans for a rational system of procurement and distribution, as well as for initiating national production of a number of basic drugs. The establishment of the State Pharmaceuticals Corporation of Sri Lanka in 1971 initiated an early package of new policies. ${ }^{9}$ A decade later, the pharmaceutical movement had so matured that a fully comprehensive, national drug policy emerged in Bangladesh in 1982.

However, this swift advance has been marked by a rising tide of opposition and pressure from the powerful international pharmaceutical industry to prevent or water down these new policy departures. These pressures have been exercised in several directions: to discredit essential drug lists and the related policies of buying drugs under generic names with the weakening or abolition of trade mark protection; to campaign in favour of industrial property rights, particularly patents and trade marks, so discouraging reform of this antiquated and unjust system; to oppose centralised bulk buying of pharmaceuticals under open international tender and the organised public distribution of drugs; and, as a condition for cooperating in the development of national industries, to press for the establishment of subsidiaries or affiliates, agreeing to some weak form of joint venture only under intense pressure, and even then maintaining severe restrictive conditions in the arrangements.

\section{Cooperation at the regional level}

The resolutions of both the 5 th and the 6th nonaligned conferences attached great importance to cooperative initiatives at the regional level. In fact, the titles of both the resolutions begin with the phrase 'cooperation among developing countries'. Progress

${ }^{9}$ The late Professor Senaka Bibile was the pioneer of this early initiative, which has continued to influence subsequent thought and action on the subject; see Bibile [1977].

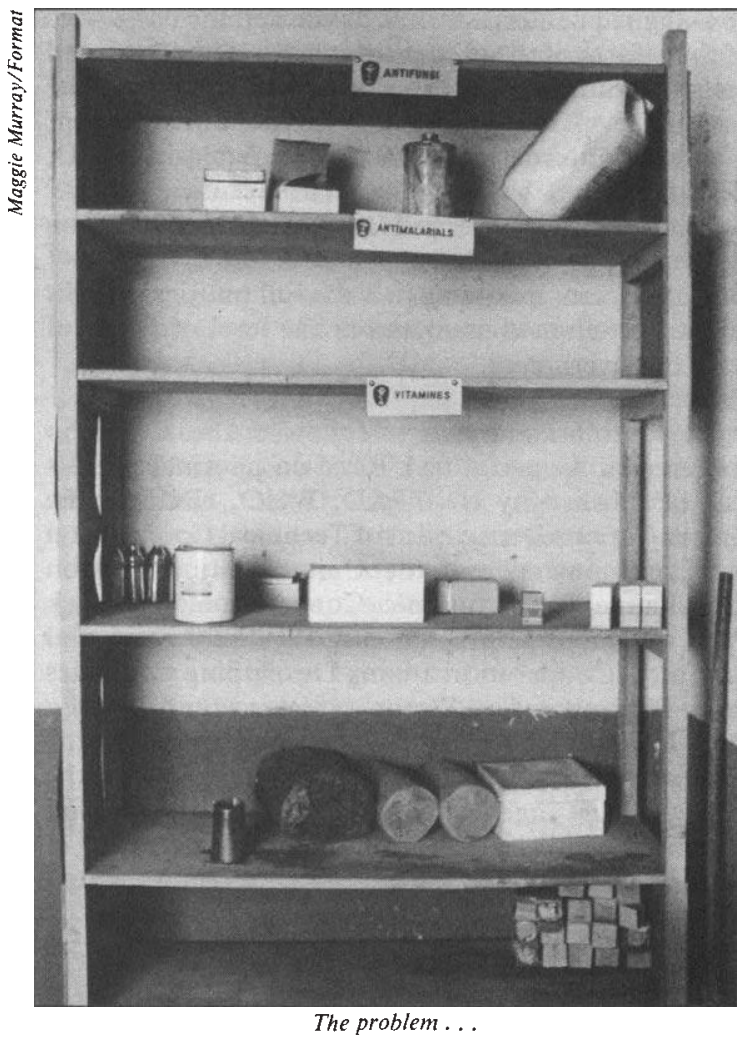

in this direction has been relatively slow, particularly because international support for strengthening economic cooperation among developing countries has begun to weaken as vested interests have intensified their opposition. The Caribbean region and the West African Economic Community appear to have moved much further along the road to regional cooperation than other parts of the world.

Caribbean region The UNCTAD and the CAICOM secretariats organised a joint mission in 1977 to visit several member countries of the region. ${ }^{10}$ The report of this mission was considered at the $4 \mathrm{th}$ meeting of the Conference of Ministers responsible for health in the Caribbean region, held in St Lucia the following year. The conference recommended the establishment of a Caribbean centre for pharmaceuticals and defined a list of functions to be performed by it.

The broad directives of the ministerial conference required detailed consideration by experts. Towards that end, a workshop on trade and technology policies

\footnotetext{
${ }^{10}$ See Towards a Regional Pharmaceusical Policy, report of a joint mission to the Caribbean region organised by UNCTAD, CARICOM and the trade, transport and industry sector of the United Nations Action Programme for Economic Cooperation, Georgetown, Guyana, August-October 1977.
} 


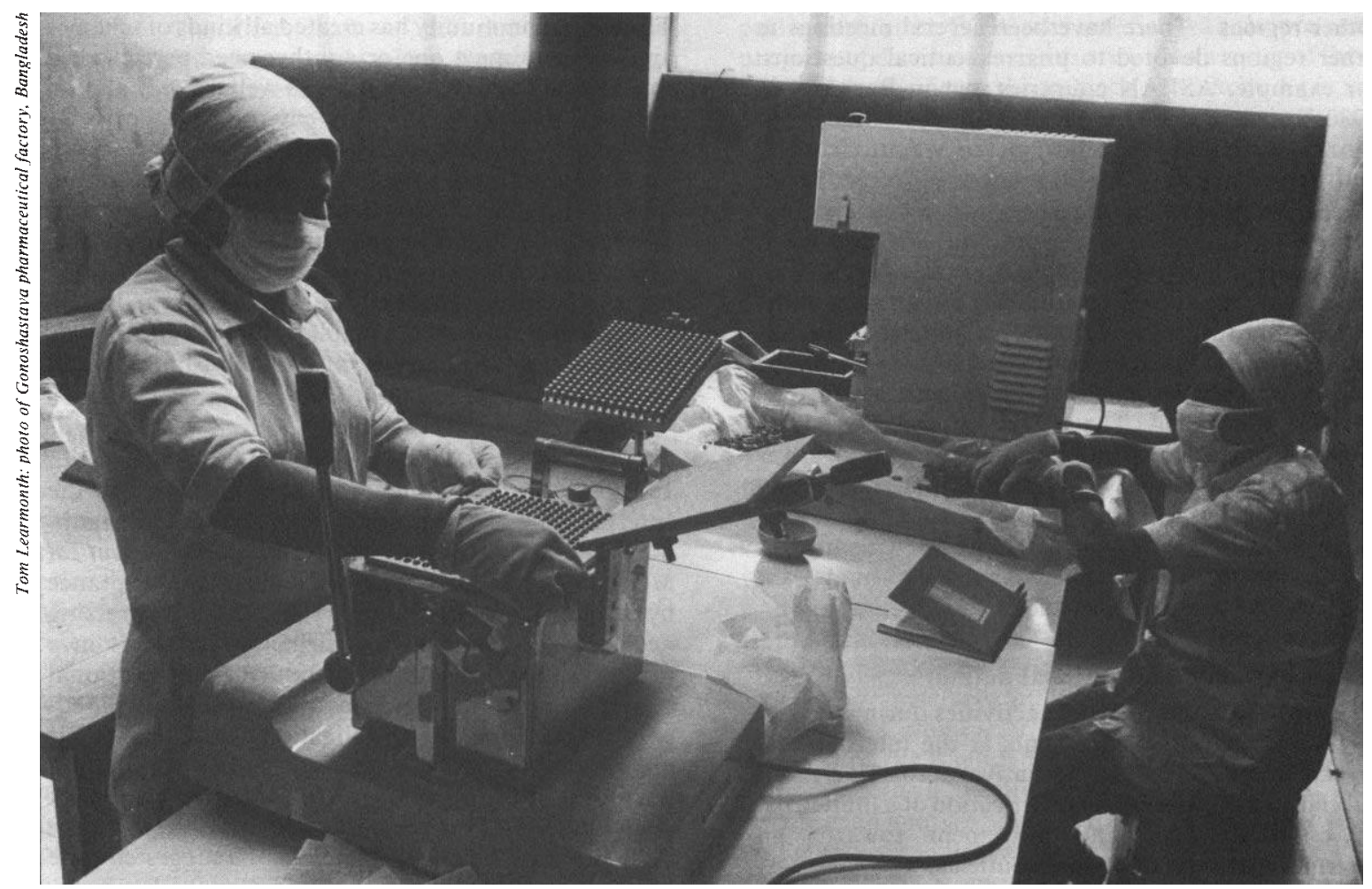

part of the solution: national drug production.

in the pharmaceutical sector in the Carribbean region was organised in 1980 in Georgetown, Guyana, by the UNCTAD advisory service on transfer of technology in cooperation with the CARICOM secretariat. The participants in the workshop were senior government officials from the region, drawn from the Ministries of Health, Planning, and Finance. They made businesslike recommendations on several important subjects, including policies on selection of drugs for pooled procurement, procedures for pooled procurement, the functions of the Caribbean centre for pharmaceuticals, alternative models for the legal structure of the centre, and a time-bound programme for the establishment of the centre. ${ }^{11}$

Of particular significance was the detailed consideration by the workshop of the alternative models for the legal structure of the cooperative centre. The workshop recommended that the model to be used should be that of an associate institution of the Caribbean Community, having its own legal status and operating as a commercial entity with powers to contract and to create financing systems. Such an associate institution, as an intergovernmental entity, would have easier access to funding and other

"For the recommendations of the workshop see UNCTAD [1980a] or UNCTAD [1982a:Annex VII]. assistance from international organisations and governments.

\section{West African Economic Community (CEAO)} UNCTAD, in cooperation with the CEAO secretariat, organised a mission in 1979 to six member count ries of the Community (Ivory Coast, Mali, Mauritania, Niger, Senegal and Upper Volta). An expert committee on pharmaceuticals discussed the report of this mission and recommended to the Council of Ministers of CEAO the creation of a technical committee on drugs to devise practical means of implementing a subregional technology policy.

Intensive discussion of the next phase of action was undertaken at a workshop on trade and technology policies in the pharmaceutical sector organised by the UNCTAD advisory service in Abidjan, Ivory Coast, in 1981. The report of the workshop helped evolve the precise content of the policies to be pursued by the countries in the West African region, and to define the scope for cooperative action at the regional and subregional levels. ${ }^{12}$

${ }^{12}$ For the recommendations of the workshop see UNCTAD [1982b:ch VI] or UNCTAD [1982a:Annex XII]. 
Other regions There have been several meetings in other regions devoted to pharmaceutical questions: for example, ASEAN countries met in Bangkok in 1980, East African countries (Madagascar, Mauritius, Mozambique and Seychelles) met in Maputo in 1981, and there have been similar activities in the South Pacific Economic Community.

All these regional initiatives have raised consciousness about the issues involved and have prepared the ground for future action. Unfortunately, there has been a great imbalance between the strength of the declared objectives and the vigour with which they have been pursued. The biggest obstacle has been posed by the weakening resource support for translating the broadly accepted schemes into fully functioning agreements and organisations. These loose threads need to be gathered up with greater vigour so that the advances already made are consolidated in the period ahead.

\section{A new phase in international action}

The upsurge of Third World activities during the late 1970s greatly influenced events at the international level. Two main groups of initiatives at this level merit special mention here: the identification of a limited list of essential drugs and movement towards an international code of pharmaceuticals.

Essential drug lists WHO established an Expert Committee on the Selection of Essential Drugs, which has issued two reports [WHO 1977, 1979]. The committee recommended an essential drug list consisting of slightly more than 200 items. It thereby cut through a confused web of some 30,000 brandname products: there is now a short list on which national policy can concentrate. ${ }^{13}$ With one bold stroke it swept away the spurious justifications, carefully cultivated and promoted at high cost, for the proliferation of brand names. Subject to the maintenance of quality standards, the fruitless debate on the virtues of brand-name versus generic products can now be deposited in the dustbin of history.

The list of essential drugs was an important step towards the Declaration of Alma Ata in 1978, paving the way for the adoption by WHO of its "Global Strategy for Health for All by the Year 2000' [WHO/UNICEF 1978; WHO 1981]. Health is now recognised as a fundamental right. Its attainment is accepted as a social responsibility. The supply of the right drugs at the right prices to all people is a key element in the strategy. Therefore, the task of devising new ways to assure such a supply has become all the more urgent.

\footnotetext{
${ }^{13}$ Such a list may, of course. be supplemented by some other
} medicaments needed for certain specific situations.
The world community has created all kinds of schemes and funds to meet one or another need perceived to call for special action: children's welfare, population control, protection of the environment, care of refugees, to cite only a few that come readily to mind. Surely health needs are no less urgent than others on which action has already been taken. If the noble goal of 'Health for All' is to be attained by the turn of this century, there is an urgent need to establish a 'United Nations Fund for Pharmaceuticals', which can be one of the mainstays of the implementation of WHO's global strategy. Proposals for its establishment merit serious consideration indeed.

Towards an international code on pharmaceuticals In 1981, under mounting pressure of events, the International Federation of Pharmaceutical Manufacturers Associations issued $A$ Code of Pharmaceutical Marketing Practices. ${ }^{14}$ This code marks an acceptance by the pharmaceutical industry that there is a pressing need for regulation in this field. It recognises in a preamble the 'pharmaceutical industry's international responsibilities' and expresses the industry's preparedness 'to accept certain obligations insofar as their marketing practices are concerned'. This recognition is an important beginning. The code itself is a brief document. After the preamble and a statement on the obligations of industry, it consists of a suggested code of marketing practices under the following headings: General Principles; Medical Representatives; Symposia, Congresses and other Means of Verbal Communication; Printed Promotional Material; and Samples. There is also a supplementary statement on the industry's commitment to observance and monitoring. The code is limited to marketing, and is to be voluntary, self-implemented, and self-monitored by the producers. ${ }^{15}$

A significant development in this area came with the involvement of the International Organisation of Consumers Unions (IOCU) and other non-governmental organisations. There was an International non-governmental conference on pharmaceuticals in Geneva in May 1981. Representatives of nongovernmental organisations, coming from 27 countries, established an international coalition called Health Action International (HAI). The 10th World Congress of the IOCU, held at The Hague in June 1981 , adopted a resolution requesting IOCU, working through HAI, to urge WHO and UNCTAD to adopt a code of practice for the marketing of pharmaceuticals.

Subsequently HAI prepared a discussion document entitled, 'A Draft International Code of Pharma-

\footnotetext{
${ }^{14}$ For the full text of the code see UNCTAD [1982a:Annex VIII] or Patel [1983, pp313-315].

${ }^{15}$ For a discussion of the limitations of the code see UNCTAD [1982a: Annex XI].
} 
ceuticals'. The first draft of the document was circulated all over the world with a view to obtaining comments from experts. It underlined the point that 'the scope of the proposed code is such that its adoption will require the expertise of various United Nations agencies, most importantly WHO and UNCTAD'.

The HAl code is based on two premises. First, since the pharmaceutical industry itself has formulated a code, the need for a code has already been recognised. However, its formulation cannot be left to the producers alone. An instrument to safeguard the interests of all parties concerned can only be evolved with the participation of consumers, public authorities and international organisations. Second, such a code cannot be limited only to marketing practices. It must embrace all other important drug issues such as trade, prices in relation to production costs, management, distribution, technology, and the entire process of research and development.

In view of its broad scope, the HAI draft code of 1982 is a very comprehensive document. ${ }^{16}$ It consists of 14 articles, most with several sub-articles, covering the areas of: drug registration; pre-registration clinical trials of new drugs; objective information on pharmaceutical products; labelling, package inserts and promotional material; sales promotion; pricing, sales and distribution; pharmaceutical technology; research and development; implementation and monitoring of the code; and a review procedure to be adopted by WHO and UNCTAD.

The subject of a pharmaceutical code was discussed at the 4th session of the UNCTAD Committee on Transfer of Technology at the end of 1982. Health Action International had requested the UNCTAD secretariat to circulate the HAI draft code to the participants in the committee meeting. The Group of 77 submitted a draft resolution requesting exploration by WHO and UNCTAD of the possibility of establishing norms and standards to govern marketing, distribution, trade and technology in the pharmaceutical sector.

The discussions in the UNCTAD Committee were inconclusive. The Group of 77 insisted on initiating the exploration of the possibility of establishing international norms and standards. They were supported by Group D, the socialist countries of Eastern Europe. Group B, the developed market economy countries, however, did not believe that this question could be settled by international norms,

\footnotetext{
${ }^{16}$ See Health Action International 1982. The text may be purchased from the publishers of the pharmaceutical news-sheet Scrip, or from Social Audit Ltd, PO Box 111, London NW1 8XG, UK. It is also reproduced in Patel (ed) [1983, pp317-328].

${ }^{17}$ For details of the discussion see UNCTAD [1983: paras 135-148].
}

particularly since WHO was satisfied with the present progress of discussions in this area. ${ }^{17}$ As a result of this divergence of views the subject was shelved, as is reflected in the second preambular paragraph to resolution 21 (IV) of the Committee on Transfer of Technology; this reads, in typical UNese: 'Noting the separate views of the Groups as expressed at the 4th session of the Committee on the formulation of international norms on promotion, distribution, trade and technology in the pharmaceutical sector'.

The question of a pharmaceutical code was taken up again at the 5th session of the meeting of the Asian Ministers of the Group of 77 in Baghdad in 1983. They adopted a Baghdad Programme of Action. Among other topics, the programme drew attention to new issues for the 1980s in the field of technology and called upon UNCTAD VI to consider 'examining the possibility of the formulation of international norms on the marketing, distribution, trade and technology in pharmaceuticals'. The Ministerial meetings of the African and Latin American regions of the Group of 77 , held respectively in Libreville, Gabon, and in Cartagena, Colombia, in 1983 also fully supported the position of the Baghdad Programme of Action. The Latin American meeting, for example, agreed 'to decide at an intergovernmental level, on the possibility of preparing international measures, norms or standards on promotion, distribution, trade and technology in the pharmaceutical sector'.

Considerable ground has now been covered on the promotion and formulation of international norms and standards - a 'code' - on pharmaceuticals. The producers have put forward their own limited version. The consumers and other interested non-governmental organisations have put forward another, much more comprehensive, draft document. Intergovernmental organisations such as WHO and UNCTAD have now been brought into the debate. The process is under way - and it will continue.

This debate recalls Hamurabi's Code. Health is such a vital concern of mankind that provisions concerning its protection saw their first expression in writing at the very dawn of civilisation in Babylon some 4,000 years ago. Hamurabi's Code, in articles 215 to 240 , prescribed different physicians' fees according to classes, and it even regulated damages for unsuccesful operations. The relevant international organisations may soon be called upon to play Hamurabi's modern role.

\section{References}

Bautista, E. and W. Clemente in cooperation with UNCTAD, 1980, Technology Policies in the Pharmaceutical Sector in the Philippines, UNCTAD/TT/36, UNCTAD, Geneva 
Bibile, S. in cooperation with UNCTAD, 1977, Case Studies in the Transfer of Technology: pharmaceutical policies in Sri l.anka, TD/B/C.6/21, UNCTAD, Geneva

Commission on Transnational Corporations, 1981, Transnational Corporations in the Pharmaceutical Industry of Developing Countries, E/C.10/85, United Nations Economic and Social Council, New York

del Bello, J. C. in cooperation with UNCTAD, 1982, Technology Policies in the Pharmaceutical Sector in Costa Rica, UNCTAD/TT/37, UNCTAD, Geneva

Health Action International, 1982, 'A Draft International Code on Pharmaceuticals', a discussion document, HAI, c/o International Organisation of Consumers Unions, PO Box 1045, Penang, Malaysia

International Centre for Industrial Studies, 1980, Assessment of the Pharmaceutical Industry 1978-2000, UNIDO/ ICIS. 146, UNIDO, Vienna

Jawaharlal Nehru University and Indian Council of Scientific and Industrial Research, 1977, Case Studies in the Transfer of Technology: the Pharmaceutical Industry in India, TD/B/C.6/20, UNCTAD, Geneva

Lall, S. in cooperation with UNCTAD, 1975, Major Issues in Transfer of Technology to Developing Countries: a case study of the pharmaceutical industry, TD/B/C.6/4, UNCTAD, Geneva

Ministry of Public Health, Cuba, 1980, Technology Policies in the Pharmaceutical Sector in Cuba, UNCTAD/TT/33, UNCTAD, Geneva

Patel, S. J. (ed), 1983, 'Pharmaceuticals and health in the Third World', World Development, special issue, vol 11 no 3

Saturno, N. A. and F. Irureta in cooperation with UNCTAD, 1982, Technology Policies in the Pharmaceutical Sector in Venezuela, UNCTAD/TT/25, UNCTAD, Geneva
UN Centre on Transnational Corporations, 1979, Transnational Corporation and the Pharmaceutical Industry, ST/CTC/9, United Nations, New York

UNCTAD, 1981, Report and Recommendations of the Workshop on Technology Policies and Planning for Technological Transformation, UNCTAD/TT/42/Rev.1, UNCTAD, Geneva

-1982a, Guidelines on Technology Issues in the Pharmaceutical Sector in the Developing Countries, UNCTAD/ TT/49, United Nations, New York

-1982b, Report and Recommendations of the Workshop on Trade and Technology Policies in the Pharmaceutical Sector, UNCTAD/TT/48, UNCTAD, Geneva

- 1983, Report of the Committee on Transfer of Technology on its Fourth Session, TD/B/C.6/79, UNCTAD, Geneva

-in cooperation with N. Anand, 1980, Technology Policies and Planning for the Pharmaceutical Sector in the Developing Countries, TD/B/C.6/56, UNCTAD, Geneva

-in cooperation with CARICOM, 1980, Report and Recommendations of the Workshop on Trade and Technology Policies in the Pharmaceutical Sector in the Caribbean Region, UNCTAD/TT/41/Rev.1, UNCTAD, Geneva

-in cooperation with National Development Corporation, Tanzania, 1980, Technology Policies in the Pharmaceutical Sector in the United Republic of Tanzania, UNCTAD/TT/35, UNCTAD, Geneva

-in cooperation with P. N. Suwal, 1980, Technology Policies in the Pharmaceutical Sector in Nepal, UNCTAD/TT/34, UNCTAD, Geneva

WHO, 1977, 'The selection of essential drugs', Technical Report Series no 615, WHO, Geneva

-1979, 'The selection of essential drugs', Technical Report Series no 641, WHO, Geneva

-1981, Global Strategy for Health for All by the Year 2000, WHO, Geneva

-and UNICEF, 1978, Primary Health Care, WHO, Geneva 